\title{
Cancer Science
}

National Cancer Institute

\section{Source}

National Cancer Institute. Cancer Science. NCI Thesaurus. Code C20187.

Systematic investigation into the causes, basic science, detection, and treatment of cancer. 